\title{
De catadores de rua a recicladores cooperados: um estudo de caso sobre empreendimentos solidários*
}

\author{
Diego Bonaldo Coelho** \\ Arilda Schmidt Godoy***
}

Sumário: 1. Introdução; 2. A economia solidária: raízes e conceitos; 3. Metodologia; 4. Apresentação e análise do caso; 5. Considerações finais.

Summary: 1. Introduction; 2. Solidary economy: the roots and concepts; 3. Methodology; 4. The case: presentation and analysis; 5 . Final considerations.

Palavras-chave: economia solidária; empreendimentos solidários; processo organizativo; desenvolvimento socioeconômico.

KEY WORDS: solidary economy; solidary enterprises; organizing process; socioeconomic development.

O artigo tem por objetivo analisar e refletir aspectos dos empreendimentos solidários e de suas potencialidades econômicas e sociais. Para sua consecução, optou-se por interpretar o processo organizativo de empreendimento solidário típico, levandose em consideração suas características particulares, que extrapolam a questão econômica, adquirindo importante dimensão social e política. A pesquisa adotou uma abordagem qualitativa, desenvolvida por meio de estudo de caso de natureza

* Artigo recebido em jul. 2009 e aceito em set. 2010.

** Doutorando em administração pela Universidade de São Paulo (USP). Mestre em administração de empresas pela Universidade Presbiteriana Mackenzie, com graduação em comércio exterior pela Universidade Presbiteriana Mackenzie e ciências sociais pela USP. Professor do Centro de Ciências Sociais Aplicadas da Universidade Presbiteriana Mackenzie. Endereço: Rua Martiniano de Carvalho, 548, ap. 83 - Bela Vista - CEP 01321-000, São Paulo, SP, Brasil. E-mail: coelhodb@yahoo.com.br.

*** Doutora, mestre e graduada em educação pela USP. Professora da Universidade Presbiteriana Mackenzie, no Programa de Pós-Graduação em Administração de Empresas, na linha de pesquisa Gestão Humana e Social nas Organizações. É pesquisadora-líder do Núcleo de Pesquisa e Formação em Administração (Nupes) do CNPq e da Universidade Presbiteriana Mackenzie. Endereço: Alameda dos Aicás, 255, ap. 101 - Moema - CEP 04086-000, São Paulo, SP, Brasil. E-mail: arilda-godoy@uol.com.br. 
interpretativista, utilizando três estratégias de coleta de dados: observação não participante, entrevistas e análise de documentos. O empreendimento escolhido para estudo foi uma cooperativa de recicláveis formada por antigos catadores de rua. A análise das informações coletadas levou em consideração dois momentos específicos da experiência estudada: sua formação e dinâmica organizacional. Concluiu-se que o caso apresenta insights e portas de entrada interessantes para se refletir os empreendimentos solidários como arranjos organizacionais que não apenas inserem marginalizados na formalidade, mas que podem influenciar positivamente aspectos sociais e políticos da vida de seus trabalhadores, tornando-se mecanismos viáveis de políticas públicas para desenvolvimento local, caracterizado pela redução da desigualdade e resgate da cidadania.

From waste pickers to cooperated recyclers: a solidary enterprise case study The article intends to analyze and reflect on solidarity enterprises aspects and their social and economic potentials. For its carrying out, it was chosen to interpret the typical solidary enterprise organizing process, regarding its particular characteristics going beyond the economic issue and acquiring important social and political dimensions. A qualitative approach of the phenomenon was used in this research, developed through interpretive nature case study with three data collection strategies adopted: non-participant observations, interviews and document examinations. The case study is on a recycling cooperative formed by waste pickers. The data analysis considered two specific points in the case study: its formation and organizational dynamic. The findings report the case presents insights and interesting gates to reflect on solidary enterprises like organization arrangements, not only including marginalized workers in formality but also influencing social and political aspects of their lives positively, becoming viable public policies mechanisms to local development characterized by inequality reduction and citizenship rescue.

\section{Introdução}

A exclusão social, por toda sua perversidade, carga simbólica e impactos, adquiriu centralidade nas principais agendas acadêmicas e governamentais, concentrando a maioria dos debates no entendimento das suas causas e, principalmente, na formulação de políticas que visem neutralizá-la, reduzindo as desigualdades, as privações e a marginalização dos indivíduos nas sociedades.

Por se tratar de problemática complexa, as causas da exclusão social não podem ser atribuídas única e exclusivamente à monocausalidade, mas a problemas sistêmicos que, direta e/ou indiretamente, atingem, em maior ou menor grau, todos os países. Na análise desses problemas, cientistas sociais e economistas (Souza, 2003; Singer, 1998a) têm apontado a crise da sociedade salarial e seu desdobramento, o desemprego, como uma de suas principais causas. 
A crise da sociedade salarial (Souza, 2003; Singer, 1998a) pode ser entendida a partir das transformações nas estruturas produtivas, ocupacionais e de emprego decorrentes das (r)evoluções ocorridas notadamente a partir dos anos 1970-80, quando da migração de uma sociedade industrial para uma informacional, em dinâmica e processos que acabaram por iniciar uma nova economia: a economia global (Castells, 1999).

Pautada pelas globalizações financeira e produtiva e por inovações tecnocientíficas, a economia global reestruturou as relações de produção, modificando ocupação e emprego, que, por suas novas configurações, acabaram por precarizar e deteriorar as antigas relações de trabalho, assim como acentuar e impor novas determinantes ao desemprego. Observa-se, nesse contexto, que parcela significativa da sociedade não consegue se recolocar e se especializar na mesma velocidade do mercado, num processo que, além de incrementar o desemprego estrutural, com exclusão de indivíduos da possibilidade formal de prover seu próprio sustento (salário), também conduz à precarização das relações de trabalho até então vigentes, levando grande contingente populacional empregado a se submeter a condições aviltantes: longas jornadas, baixa remuneração, desproteção legal e instabilidade (Souza, 2003).

Em contrapartida a esse cenário, alternativas e ações para provimento de trabalho, emprego formal, renda e redução da exclusão começaram a ser discutidas em escala global. Entre essas, encontra-se o ressurgimento do debate em torno da organização coletiva do trabalho (Singer, 1999, 2000, 2002, 2003).

A organização coletiva do trabalho é caracterizada por diversas práticas e formas organizacionais que têm por objetivo associar pessoas para produzir e reproduzir meios de vida com base em relações de reciprocidade e igualdade (Cunha, 2003). A forma típica desse tipo de organização é a cooperativa, cujos meios de produção estão nas mãos dos trabalhadores, sendo sua gestão democraticamente conduzida por eles.

No Brasil, grande parte dessas organizações encontra-se no âmbito da economia solidária, das quais se destacam as associações comunitárias e as cooperativas populares. Como aponta Silva Júnior (2004), essas organizações passaram a contemplar um triplo plano de atuação (social, econômica e política), permitindo que estas sejam entendidas como empreendimentos solidários (Gaiger, 1996, 2003).

Nesse contexto, a economia solidária e seus empreendimentos têm despertado séries de estudos e reflexões nas ciências sociais aplicadas brasileiras. A maioria desses estudos, focados na problemática da exclusão social, concentra-se na análise dos impactos desses empreendimentos no mercado de 
trabalho e, consequentemente, de seu papel no desenvolvimento econômico e social do Brasil (Culti, 2002; Nascimento, 2004; Singer, 1998b, 2000, 2002).

Não obstante, duas novas frentes de pesquisa, destacadamente nos estudos organizacionais, começam a ganhar importância recentemente. A primeira trata de estudos que se voltam para o debate teórico-conceitual desses empreendimentos, buscando entendê-los em suas manifestações e formações (arranjos) organizacionais na sociedade (França Filho, 2002; Gaiger, 1996, 2003). A segunda, bem representada nos trabalhos de Oliveira (2005) e Liboni (2002), direcionada às influências que esse tipo de empreendimento pode gerar em seus membros. Nessas duas frentes, pesquisas têm se desenvolvido pelo diálogo entre as ciências sociais aplicadas e humanas, tais como a administração, a economia, a sociologia, a antropologia e a psicologia.

$\mathrm{O}$ presente artigo apresenta um estudo inspirado nessas frentes de pesquisa, com destaque para aquelas que atentam para as questões organizacionais destes empreendimentos. Seu principal objetivo é analisar as questões socio-organizacionais de um empreendimento solidário a partir da perspectiva interpretativa, a fim de contribuir para o debate sobre a formação e a dinâmica desses empreendimentos no Brasil e de seus impactos nos indivíduos, suscitando até que ponto é possível considerá-los mecanismos de inserção econômica e social.

Por meio dessa perspectiva e abordagem interdisciplinares, desenvolveu-se a pesquisa aqui apresentada, que buscou atender aos seguintes objetivos específicos: (a) compreender e descrever como foi formado e atualmente é vivenciado um empreendimento solidário; (b) analisar e interpretar o processo organizativo e a dinâmica organizacional do empreendimento estudado; (c) identificar o possível impacto deste empreendimento na vida de seus membros.

Desse modo, considera-se a interpretação de um processo organizativo (Spink, 1991, 1996) como oportuna para propiciar uma reflexão acerca dos vários aspectos envolvidos nos empreendimentos solidários — sua formação, sua dinâmica organizacional, sua gestão, seus indivíduos e relações com a sociedade, vez que tal conceito entende as organizações como processo social, direcionando esforços de análise

para pensar como pessoas interagem para definir objetivos e para construir os meios para atingi-los, como constroem regras, rotinas e procedimentos num contexto conformado por duas ordens de realidade: de um lado pelo fato de as pessoas terem suas histórias de vida, suas expectativas e visões de mundo e também suas necessidades materiais particulares de sobrevivência; de ou- 
tro, esse contexto também é conformado pelos recursos de que se dispõe, pela tecnologia que se domina, pela realidade de mercado e pela racionalidade econômica que vigoram como parâmetros para as relações nessa sociedade (Sato, 1999:20).

O caso selecionado para estudo foi a Cooperlírios, situada na Região Metropolitana de Campinas [RMC], na cidade de Americana, interior de São Paulo. A Cooperlírios é uma cooperativa de seleção e processamento de materiais recicláveis formada por antigos catadores de rua.

A abordagem metodológica adotada para estudo do fenômeno foi qualitativa, desenvolvida por meio de um estudo de caso de natureza interpretativista, sendo utilizadas três estratégias de coleta de dados: observação não participante; entrevistas e análise de documentos.

Buscou-se, com isso, analisar e interpretar fenômenos organizacionais numa perspectiva e abordagem que extrapolam o instrumentalismo prescritivo e a vertente gerencialista da administração, pautados pelas clássicas descrições de modelos e fórmulas de gestão. Adentrou-se pelo terreno intersubjetivo das organizações, principalmente no que concerne às relações estrutura-indivíduos, levantando insights e portas de entrada interessantes para se refletir sobre esse tipo de experiência.

O artigo trata, no próximo item, da economia solidária, no qual são conceitualmente apresentadas as origens desse movimento, seu desenvolvimento e manifestações, tomadas as cooperativas enquanto forma e modelo de empreendimentos solidários por excelência. No item 3, descreve-se a metodologia de realização da pesquisa e, seguidamente, no item 4, constrói-se a apresentação e análise do caso estudado. Fecha-se o texto com a interpretação dos fenômenos observados, destacando insights e relacionando o caso estudado com o referencial teórico da economia solidária, empreendimentos solidários e novas perspectivas sobre participação, solidariedade e inserção social.

\section{A economia solidária: raízes e conceito}

\subsection{Em busca das raízes}

A economia solidária e seus consequentes conceitos, movimentos e práticas possuem raízes comuns, arraigadas na Questão Social (Iamamoto, 2001) deflagrada pelos impactos sociais, políticos e econômicos quando da ascensão e consolidação do capitalismo. 
A questão social (Iamamoto, 2001) adquiriu dimensão e relevância durante a constituição da sociedade capitalista, tendo em vista a dinâmica conflituosa entre capital e trabalho característica desse modo de produção, que, ao subjugar o segundo ao primeiro, acabou por originar novas relações sociais de produção, caracterizadas em seu início pela exploração e pela alienação. Nessas novas dinâmicas e estrutura sociais, grande contingente de trabalhadores ficou recluso à miséria, em condições subumanas, excluído da possibilidade de viver dignamente (Engels, 2002).

Os trabalhadores, antes de perceberem e de se revoltarem pela extinção da alienação do próprio ato produtivo, reagiram primeiramente pelos excluídos, opondo-se à exploração e às severas restrições à possibilidade de subsistir nas próprias regras do sistema (vendendo sua força de trabalho), e, no segundo momento, por inserção política mais positiva na sociedade. As principais e notórias manifestações e reivindicações dos trabalhadores alinhadas com essa pauta foram o luddismo e o cartismo (acesso ao emprego, melhores condições de vida, direitos políticos, dignidade ao trabalhador, entre outros), e nessas primeiras reações se colocaram as raízes do discurso que fundamenta a economia solidária. Entretanto, enquanto prática mais articulada e sustentável, suas raízes encontram-se em outro importante movimento iniciado concomitantemente a estas lutas: a organização coletiva do trabalho.

A organização coletiva do trabalho nasce da reflexão sobre essa perversa questão social que se configurava. Pensadores começaram a indagar sobre o funcionamento estrutural do capitalismo e de seus impactos no contexto social (exclusão), o que, aos poucos, acabou por formar correntes de pensamento que buscavam refletir e prescrever saídas para essa situação legada aos trabalhadores, tida como insustentável.

Buber (2005) destaca seis principais pensadores que contribuíram em gerações distintas para a construção de um pensamento reflexivo e proativo na luta contra a dinâmica capitalista, propenso à reestruturação da sociedade e à inserção social positiva: Saint-Simon (1760-1825); Fourier (1772-1837); Owen (1771-1858); Proudhon (1809-1865); Kropotkin (1842-1921) e Landauer (1870-1919).

Por meio da análise do pensamento desses autores encontram-se reflexões acerca de nova forma de organização do trabalho oposta ao ideário do chão de fábrica capitalista, sendo possível constatar com mais clareza o primado da economia solidária. São reflexões voltadas para uma forma de organização do trabalho que, por ser coletiva, apresenta características organizacionais que extrapolam a mera dimensão econômica, carregando consigo uma dimensão política e social de caráter idealmente transformador. 
Na perspectiva histórica e crítica de alguns autores, como Singer (1998b, 2000), a consolidação desse tipo de organização é, no limite, pilar de potencial contrarrevolução à revolução capitalista. Como analisa o autor, do mesmo modo que houve uma revolução social capitalista que, por meio de avanços tecnológicos, consolidou novas relações de produção, fundando uma nova sociedade com resultados inicialmente perversos à classe trabalhadora, há também uma potencial revolução social socialista em curso. Uma revolução social enquanto processo de mudanças estruturais lentas, que se iniciou na Inglaterra, há dois séculos, por meio da formação de sindicatos, aprovação de legislação trabalhista, sistema de seguridade social e, notoriamente, das cooperativas. A consolidação da organização coletiva do trabalho é, portanto, nessa visão, um movimento político e social de fundamentos e princípios opostos ao capitalismo, adquirindo dimensão socialista (Singer, 1998b, 2000, 2003).

Pode-se dizer, então, que as raízes discursivas e práticas da economia solidária confundem-se com as reações da classe trabalhadora à exploração do capitalismo, sendo, nesse sentido, frutos do custo humano da Revolução Industrial. Contudo, a despeito dessas raízes estarem na reação operária e intelectual aos resultados do capitalismo, observadas no desenvolvimento de iniciativas empreitadas em defesa do trabalhador e, principalmente, na organização coletiva do trabalho, o conceito de economia solidária é dado a posteriori, extemporâneo às suas raízes. $\mathrm{O}$ conceito de economia solidária é uma noção atual, mais ampla e acabada, que absorve de maneira crítica todas essas experiências, carregando em si a síntese de um debate que incorpora várias experiências de reação ao capitalismo a partir de ações que possuem como seu ponto central e fundamental a organização coletiva do trabalho.

\subsection{Em busca do conceito}

A organização coletiva do trabalho no âmbito da economia solidária remete às experiências de economia social influenciadas pelos pensamentos socialistas, as quais são caracterizadas pela associação de pessoas em gestões democráticas para produzir e reproduzir meios de vida, segundo relações de solidariedade, reciprocidade e igualdade. As três formas principais dessa economia são as cooperativas, as mutualidades e as associações.

De acordo com Wautier (2004:65), a economia social trata de

um conjunto de organizações e empresas cujas atividades produtivas respondem a princípios prioritários: adesão livre, democracia interna (uma pessoa, 
uma voz), lucratividade limitada (reinvestimento dos excedentes na ação social e não lucratividade individual dos associados), respeito da dimensão humana da atividade e solidariedade.

Ao se incorporar a leitura de todos os clássicos socialistas e as experiências vividas até então na Europa de economia social, forja-se o conceito mais preciso de economia solidária. De acordo com França Filho (2002), os autores que se incumbiram de tal tarefa foram Jean-Louis Laville e Bernard Eme. Laville constrói o conceito de economia solidária como

conjunto de atividades econômicas cuja lógica é distinta tanto da lógica do mercado capitalista quanto da lógica do Estado. Ao contrário da lógica capitalista, centrada sobre o capital a ser acumulado e que funciona a partir de relações competitivas cujo objetivo é o alcance de interesses individuais, a economia solidária organiza-se a partir de fatores humanos, favorecendo as relações onde o laço social é valorizado através da reciprocidade e adota formas comunitárias de propriedade. Elas se distinguem também da economia estatal que supõe autoridade central e formas de propriedade institucional (Laville apud Lechat, 2002:5).

França Filho (2002) aponta que esse novo conceito foi utilizado para tentar dar conta da forte emergência e proliferação de diversas iniciativas e práticas socioeconômicas na Europa, as quais estavam assumindo a forma associativa e tinham como objetivo responder a certas problemáticas locais específicas. A economia solidária, pois, não remete apenas a iniciativas econômicas associativas da economia social, mas incorpora o objetivo claro de responder a certas problemáticas locais específicas, trazendo elementos relevantes para entendê-la como conjunto de iniciativas econômicas caracterizadas por serem meios pelos quais se busca realização de fins sociais (França Filho, 2002). Com isso, alarga-se em movimento de dimensões políticas e sociais, que extrapola a mera organização coletiva do trabalho. Esse alargamento pode ser apreendido pela diferenciação tipológica dos conceitos de economia social e economia solidária de Wautier (2004).

Como demonstra a autora, os conceitos de economia social e economia solidária são muitos próximos, contudo existe pequeno ponto que permite diferenciação, dando maior peso político e social contemporâneo à economia solidária. Para Wautier (2003:110), a economia solidária incorpora a economia social completamente e "acentua a noção de projeto, de desenvolvimento local e de pluralidade das formas de atividade econômica, visando à utilidade 
pública, sob a forma de serviços diversos, destinados, principalmente, mas não exclusivamente, à população carente ou excluída".

Nesse sentido, a economia solidária, ao tratar de iniciativas de organizações coletivas e solidárias para superar dificuldades estruturais locais promotoras de exclusão, carrega em si dois termos que são noções historicamente dissociadas (iniciativa econômica e solidariedade) que acabam se incorporando, colocando a solidariedade na elaboração de atividades econômicas coletivas e locais (França Filho, 2002).

As iniciativas de economia solidária invertem os princípios da economia tradicional de concentração de riquezas, tornando-se formas de luta política de grupos da sociedade para a instituição de nova relação com a economia. Constituem-se em movimento complexo que, por suas características, é destacadamente composto pelas dimensões econômica, política e social.

Essas iniciativas, portadoras do discurso e da prática da economia solidária, podem ser entendidas como empreendimentos solidários (Gaiger, 1996, 2003). Conforme Gaiger (1996, 2003), esse tipo de empreendimento apresenta as características ideais de: autogestão; democracia; participação; igualitarismo; cooperação; autossustentação; desenvolvimento humano e responsabilidade social.

Observa-se que a complexidade do fenômeno economia solidária e seu desafio encontram-se nas características que suas iniciativas de organização coletiva do trabalho (empreendimentos solidários) possuem em equilibrar distintas e diversas lógicas que a atravessam. Por se tratar de iniciativas coletivas e solidárias de organização do trabalho para problemas locais, elas não podem ser observadas estrita e exclusivamente pela ótica da racionalidade econômica. Os empreendimentos solidários encontram-se na problemática que determina dois traços característicos (hibridação de economias e construção conjunta da oferta e da demanda) que se apresentam em uma forte tensão entre três economias (mercantil, não mercantil e não monetária) e duas lógicas (instrumental e substantiva) (França Filho, 2002). Para observar essas distintas lógicas, França Filho (2002) propõe a visão polanyiana, com base na economia plural.

De acordo com França Filho (2002), a relevância de se interpretar as experiências dos empreendimentos solidários da economia solidária pela economia plural ocorre pelo fato de não se reduzir ao mercado e a uma única racionalidade econômica de visão neoclássica esse tipo de empreendimento, que detém dimensões além da econômica. A economia plural é conceito desenvolvido por Polanyi que extrapola a existência de apenas um comportamento econômico, incorporando pluralidade de princípios. Para Polanyi, 
conforme desenvolve França Filho (2002), existem quatro grandes princípios do comportamento econômico: o mercado autorregulado, a redistribuição, a administração doméstica e a reciprocidade. Esses princípios resumem-se a três formas de economias: mercantil, não mercantil e não monetária. A economia mercantil caracteriza-se pelo princípio do mercado autorregulado. Nesse caso, as trocas são marcadas pela impessoalidade e pela equivalência monetárias. As trocas, assim, são dadas por características utilitaristas que visam o estabelecimento de valores de trocas dos bens por seus preços/utilidades. Já a economia não mercantil funda-se no princípio da redistribuição. Ela é marcada pela verticalização das trocas e tem caráter obrigatório. Existe, nesse caso, a figura de uma instituição superior, como o Estado, que se apropria de recursos com objetivo de distribuição. E, finalmente, a economia não monetária, que se fundamenta pelo princípio da reciprocidade. Nessa economia, as trocas são pela lógica da dádiva maussiana, constituída por: dar, receber e retribuir. Assim, a circulação dos bens tem por objetivo constituir e manter laços sociais de reciprocidade.

Desse modo, observar a noção de economia plural é ultrapassar a ideia da economia de mercado como única fonte de riqueza, identificando-a entre três polos de complementaridade. É pensar em forma de produção e distribuição de riqueza "não necessariamente contra o mercado, mas a seu favor, entretanto sob a condição de que o mercado seja submetido a outros princípios, ou melhor, que esteja engastado ou enraizado junto a outros registros de práticas" (França Filho, 2002:6).

Logo, pode-se entender a economia solidária como um fenômeno de forma singular de organização e atuação que, pela organização coletiva do trabalho, constitui espaço que não é só econômico, mas de recuperação e de ressignificação de valores e práticas sociais sucateadas e esquecidas pelo capitalismo. Ao propiciar a inclusão e a reconstrução pessoal dos indivíduos excluídos (Gaiger, 1996, 2003), proporciona novas iniciativas locais portadoras de outro modo de funcionamento e finalidades, reunindo personagens preocupados em articular inserção econômica positiva com fins de estabelecimento de liame social (França Filho, 2002).

\subsection{Economia solidária no Brasil}

As iniciativas de empreendimentos da economia social disseminados pelo Brasil, por meio de cooperativas de vários ramos, bancos comunitários, associações, sejam no campo ou na cidade, em reação às crises dos 1970-80 e 1990- 
2000, começaram a se confirmar e aos poucos constituir em seu conjunto a economia solidária no país. Consequentemente, deu-se o início desse tipo de empreendimentos solidários como alternativa (Gaiger, 1996, 2003). De acordo com Singer (2000:25), "a economia solidária ressurgiu, de forma esparsa, na década de 1980 e tomou impulso na segunda metade dos anos 1990, resultando em movimentos sociais de reação à crise de desemprego em massa, em 1981, e se agravando com a abertura do mercado interno às importações, a partir de 1990".

Destacadamente nos anos 1990, a economia solidária nasce no Brasil como movimento pela inclusão no mercado de trabalho, diretamente ligada ao contexto de crise econômica e exclusão social e suas consequências, como o desemprego, a marginalidade, a precarização e a informalidade.

Foi no governo Lula que a economia solidária acabou por assumir seu caráter mais estrito. Tornou-se política pública deliberada, ganhando sua mais forte institucionalização federal. No ano de 2003, no âmbito do Ministério do Trabalho e Emprego (MTE), criou-se a Secretaria Nacional de Economia Solidária (Senaes). O principal objetivo da Senaes é "promover o fortalecimento e a divulgação da economia solidária, mediante políticas integradas, visando à geração de trabalho e renda, inclusão social e promoção do desenvolvimento justo e solidário" (Brasil, 2006).

Nessa linha política, a economia solidária no Brasil começa a se constituir como movimento que busca e propõe iniciativas para superar as crises social e econômica que geraram grande desigualdade e exclusão sociais. Para isso, alimenta-se de nova expressão do movimento cooperativista (Singer, 1999, 2000; Nascimento, 2004), que extrapola a economia social (Wautier, 2004), sustentando-se nos empreendimentos solidários (Gaiger, 1996, 2003).

O discurso da economia solidária brasileira idealmente se pauta pelo valor atribuído à democracia, igualdade e autogestão dentro dos empreendimentos, portando para si uma espécie de ressurreição de valores que fazem parte da cultura do movimento operário: solidariedade, autogestão, autonomia, mutualismo, economia moral e outros (Nascimento, 2004).

\section{Metodologia}

Tendo em vista as características da problemática explorada, para este estudo foi utilizada a abordagem qualitativa, que está interessada em examinar quais os significados que os indivíduos atribuem ao fenômeno e/ou situação estudada (Merriam, 1998). Optou-se pelo desenvolvimento de um estudo de 
caso, o qual está cada vez mais difundido nas ciências sociais aplicadas, particularmente nos estudos organizacionais, conforme atesta o trabalho de Godoi e Balsini (2006).

Utilizou-se de estudo de caso de natureza interpretativista, à luz de Stake (2000), Hartley (1999) e Merriam (1998), dado o espaço de reflexão, interpretação e insights que este tipo de método possibilita. A pesquisa de campo apoiou-se em três estratégias fundamentais: observação não participante, análise de documentos e entrevistas.

A observação foi conduzida por uma participação sistemática no campo, de característica não participante (Godoy, 2006). Diferentemente da observação participante inspirada nos trabalhos do antropólogo Malinowski, na qual o pesquisador deixa de ser espectador e passa a assumir funções no campo, misturando-se a ele, no presente estudo, embora o pesquisador tenha integrado o campo, isso foi feito de maneira mais distante, no papel de atento espectador.

A observação não participante executada neste estudo ocorreu por meio de visitas regulares ao longo de cinco meses, que tiveram por objetivo acompanhar um pouco do ato de trabalhar na seleção de materiais recicláveis, observar o local de trabalho, participar de algumas reuniões e assembleias, bem como executar as entrevistas com os cooperados. Os principais instrumentos utilizados nessa observação foram o diário de campo e a documentação midiática (pequenas filmagens e fotos).

Pela tomada lato sensu da documentação de qualquer organização como sua cultura material, considerou-se aqui os documentos como expressões materiais da origem e razão de ser da organização (Estatuto), bem como de toda sua dinâmica registrada (Regimento Interno, Atas, estatísticas etc.). Foram objetos de análise os seguintes documentos: Estatuto; Regimento Interno; Atas; e Convênio Prefeitura-Cooperativa.

As entrevistas foram semiestruturadas e realizadas a partir de um roteiro. O roteiro de entrevistas objetivou estruturar uma conversa fluida que estimulasse o indivíduo a reconstruir um pouco de sua história pessoal, sua trajetória e vivência no trabalho e no empreendimento, bem como os possíveis reflexos dessas experiências em sua vida. No limite, explorou a vivência do cooperado na construção do empreendimento em questão. O roteiro estava dividido em quatro blocos, embora em sua utilização no transcorrer da entrevista fosse respeitada a sequência narrativa estabelecida pelo próprio entrevistado.

$\mathrm{O}$ número de indivíduos entrevistados não foi pautado por amostragem estatística. Buscou-se entrevistar número considerável de cooperados, não levando em consideração nenhum filtro específico. Apenas, a título de homoge- 
neidade, as entrevistas focaram os cooperados mais assíduos no trabalho e se distribuíram relativamente igualitárias em tempo de organização a partir de dois grupos: cooperados recentes e cooperados mais antigos. Foram feitas 12 entrevistas no total. A primeira delas foi de cunho exploratório e foi feita com a presidente em exercício da cooperativa, antes mesmo da elaboração do roteiro. Com o roteiro finalizado, foram entrevistados 10 cooperados, de um total de 20 , dos quais cerca de 15 eram realmente ativos. A última entrevista foi feita com um vereador do Legislativo da Prefeitura Municipal de Americana (SP), tendo em vista seu envolvimento direto no projeto do empreendimento, apresentando-se como principal articulador entre a Prefeitura Municipal e a cooperativa.

A análise dos dados pautou-se na metáfora do pesquisador qualitativo como bricoleur (Denzin e Lincoln, 1994). Pretendeu-se aproximar o processo de análise de dados qualitativos pela dinâmica encontrada na definição do bricoleur como aquele "que executa um trabalho usando meios e expedientes que denunciam a ausência de um plano preconcebido e se afastam dos processos e normas adotados pela técnica" (Lévi-Strauss, 1976:32). Com isso, atribui-se ao processo de análise a possibilidade de ser conduzido não por uma lógica científica positivista e predeterminada em rígidas etapas, mas de se caminhar abertamente para a construção de uma interpretação não concebida aprioristicamente. Afastam-se de seu resultado características herméticas e restritas, tornando-o fruto relativamente livre da coleta de fragmentos acumulados nas experiências manifestadas no campo, "causos" e histórias compactuados em terreno intersubjetivo, sendo, dessa maneira, uma leitura à moda do pesquisador, uma interpretação para o fenômeno em seu contexto.

Essa bricolage, em sua dinâmica, foi tecida da seguinte forma: todos os documentos da cooperativa acessados foram observados em seu contexto cultural e operacional, e comparadas as suas letras a suas dinâmicas na práxis. As observações e diálogos do pesquisador em campo possibilitaram construir uma interpretação das entrelinhas dadas em contexto, além de sugerir portas de entradas para insights de análise do fenômeno. Finalmente, as entrevistas semiestruturadas, com papel preponderante nessa construção interpretativa, tiveram seus resultados tratados como narrativas construídas pelos cooperados. Optouse, então, para corroborar a atividade de bricolage à análise das entrevistas, tomar as narrativas dos cooperados como crônicas (Coffey e Atkinson, 1996).

\section{Apresentação e análise do caso}

Dois processos tornaram-se relevantes para análise da cooperativa estudada: sua formação e sua dinâmica organizacional. Estes se justificaram, pois a his- 
tória da concepção, do início de seu processo organizativo, bem como de sua dinâmica, apresenta pontos e momentos interessantes de análise, abarcando não apenas o caso em si, mas resgatando o debate teórico da economia solidária, seus empreendimentos, suas potencialidades e seus impactos socioeconômicos.

\subsection{Formação}

A formação da cooperativa, o início de seu processo organizativo, desdobrouse da interação entre a Prefeitura Municipal de Americana e a comunidade periférica da favela da Vila Martins, quando das primeiras intervenções locais do setor público na execução de política de desenvolvimento urbano para a região. Por ser uma região considerada em situação de risco, sendo marcada por invasões, irregularidades e precariedade de moradia (barracos e autoconstruções), o planejamento da política de desenvolvimento da Prefeitura para a favela inicialmente focou suas ações no provimento de habitações (política habitacional), as quais ocorreram por meio da organização de mutirões.

Por se tratar de empreitada coletiva baseada na ajuda mútua, a dinâmica dos mutirões promove interação social. No caso da favela da Vila Martins, a organização dos mutirões e sua realização acabaram por desenvolver certa aproximação entre os envolvidos, estabelecendo contato (diálogo e relações) que permitiu à prefeitura observar mais detalhadamente os problemas e as demandas locais, revelando alguns pontos além da questão habitacional. Uma das principais questões detectadas nessa interação emergiu da problemática da salubridade.

A despeito da situação precária da higiene em moradia inapropriada (barracos e autoconstruções, ausência de saneamento básico, de esgoto, de asfalto etc.), foi constatada a presença de grande carga de entulho e lixo nas zonas residenciais, que acabava por se tornar refúgio de insetos, roedores e outros vetores de zoonoses. Ao se estudar a origem desses entulhos e lixos, os agentes da prefeitura descobriram se tratar do resultado da atividade de coleta de matérias recicláveis e/ou reutilizáveis por parcela considerável das famílias locais.

De maneira caótica e desmedida, os catadores saíam à revelia pelas ruas da cidade, "catando" todo tipo de material que pudesse gerar alguma renda de sua venda. Ao final do dia, acabavam por utilizar seus próprios barracos e/ou autoconstruções precários como armazém. Consequentemente, por não serem número desprezível e não trabalharem em lugares específicos e/ou organiza- 
dos, a atividade desses catadores transformou as residências em ambientes extremamente insalubres, tanto para seus moradores, como para seus vizinhos.

A precariedade desse trabalho de coleta, que em sua dinâmica trazia pequeno ganho para o catador e gerava externalidades negativas ao saneamento e à salubridade locais, sensibilizou os agentes públicos envolvidos no projeto de mutirões. O que era para ser política de desenvolvimento urbano focada apenas em habitação, alargou-se, tornando-se ação integrada e sustentável: habitação e urbanização com restauração e preservação da salubridade e provimento de condições dignas para os catadores continuarem suas atividades.

Como primeira ação, uma assistente social da prefeitura percorreu toda a favela, de porta em porta, cadastrando e convocando todos os catadores para comparecerem a uma série de assembleias comunitárias presididas pelos agentes da prefeitura, com vistas a se discutir possibilidades para equacionar o problema gerado por suas atividades.

As primeiras assembleias foram caracterizadas pelo estreitamento do diálogo entre as partes. A principal intenção da prefeitura era trocar experiências e conhecer quem eram esses catadores e qual a dinâmica de suas atividades, ou seja, informar-se e aprender a respeito desse grupo social.

Tendo em vista as poucas iniciativas e experiências desse tipo de diálogo do setor público brasileiro com sua comunidade mais próxima, somada, ainda, a inércia da baixa participação política dos brasileiros nesse tipo de processo, as primeiras assembleias não obtiveram a atenção e a consideração política esperadas dos catadores. Conforme relato de uma catadora, os primeiros encontros foram bons para eles, pois "tinha lanche e eles davam almoço". A fala sincera, em referência à relevância das assembleias estar apenas no lanche, apresenta dois pontos importantes de análise. O primeiro, da corroboração de que a população que sobrevive da coleta de materiais recicláveis e reutilizáveis está em situação social de risco, na maioria das vezes abaixo da linha da pobreza. A existência de um lanche gratuito fornecido pelo Estado, seja em qual âmbito for (federal, estadual ou municipal), acabou por se tornar atrativo àqueles que não possuíam condições de ter todas as suas refeições no dia. Já o segundo ponto trata da questão do estranhamento no início do diálogo entre a prefeitura e os catadores, vez que a convocação dos catadores partiu da prefeitura, levando os primeiros diálogos a serem distantes e pouco entrosados. Como em todo "assembleísmo", há um tempo para maturar a interação e as discussões serem mais participativas e, principalmente, propositivas.

Com o passar das primeiras assembleias, os diálogos entre a prefeitura e os catadores foram se estreitando. Foi possível, por exemplo, discutir com 
maior propriedade a dinâmica dos catadores no cotidiano da atividade de coleta de materiais nos lixos das casas da cidade.

A primeira maturação desse processo ocorreu quando a prefeitura começou a esboçar a possibilidade de organizar a atividade de coleta, permitindo a utilização do espaço da olaria comunitária construída para fornecer tijolos aos mutirões das casas populares como um galpão que abrigasse esses catadores. Essa ação visava garantir a manutenção da atividade econômica no local, possibilitando que esta fosse executada de modo mais organizado, retirando a armazenagem das moradias. Os catadores exerceriam suas coletas normalmente pela cidade e teriam à disposição um galpão para armazenagem e seleção de seus materiais.

Com a concessão da utilização do galpão pelos catadores, observou-se movimento interessante: constatou-se certa migração de atividades. A existência de espaço público para exploração de atividades privadas pelos indivíduos que exerciam a coleta de materiais recicláveis e/ou reutilizáveis deslocou a grande maioria dos catadores locais para esse espaço, incentivando, inclusive, o surgimento de "novos" catadores — indivíduos desempregados que vislumbraram, nesse momento, relativa oportunidade de trabalho para geração de renda.

O galpão acabou por se tornar espaço disputado que, em pouco tempo, já não comportava de modo satisfatório e organizado as atividades de coleta. Os catadores passaram a disputar severamente seu espaço, entrando, muitas vezes, em conflito.

Nesse momento, agentes da prefeitura, incentivados pelas experiências que visitaram em outras cidades da região por conta do problema, colocaram em pauta a possibilidade de organizar essas atividades (trabalho) por meio de uma cooperativa. De acordo com o vereador líder e precursor desta ideia, a escolha da cooperativa como forma de organizar o trabalho foi pautada pela avaliação positiva desse modelo pela prefeitura, que vislumbrou ser este o mais sólido e sustentável para alcançar os objetivos institucionais e gerenciais do trabalho de coleta e seleção de recicláveis e/ou reutilizáveis no local, bem como para prosperidade de seus trabalhadores. Nesse entendimento, a cooperativa seria uma resposta organizacional adequada para dar forma mais eficaz e sustentável ao caso.

Após algumas assembleias de exposição sobre o que seria uma cooperativa e os ganhos que os catadores poderiam conquistar atuando nessa forma de organização, chegou-se, finalmente, à votação favorável por sua implantação. Em uma assembleia lotada, nos idos de 1999, uma salva de palmas rompeu o silêncio da noite, aclamando o nome escolhido para o mais novo empreendimento do bairro: Cooperlírios. 
O nome Cooperlírios carrega em si dois termos: o Cooper e os Lírios. Os Lírios são uma referência clara ao local de instalação do empreendimento, o loteamento popular Jardim dos Lírios que deu nome ao bairro após a urbanização de sua favela (Vila Martins). Já o prefixo Cooper é uma denominação do tipo de empreendimento fundado, uma cooperativa.

Ao se analisar o princípio motivador da formação da Cooperlírios, é possível desdobrar debate que reinaugura a questão entre revolucionários versus reformistas sobre o surgimento deste tipo de empreendimento: seria, neste caso, um princípio revolucionário a iniciativa de contestar a exploração do sistema capitalista por meio da organização da sociedade civil em bases socialistas de produção, ou um princípio pragmático, de se constituir uma alternativa reformista viável para se resolver a questão do desemprego?

As indagações acima possuem suas justificativas no próprio histórico do surgimento do cooperativismo, o qual, como analisado, foi marcado em seu início pela existência de forte discurso revolucionário por detrás das ações de formação das primeiras organizações cooperativas. Tanto nas primeiras empreitadas do cooperativismo na Europa do século XVIII quanto atualmente ainda propugnam alguns dos órgãos e sindicatos de trabalhadores ligados ao cooperativismo e à economia solidária; a principal motivação que incentiva a iniciativa de formação de empreendimentos solidários está na contestação do capital (Marx, 1995) e do sistema capitalista. A própria análise de Singer (2000) corrobora tal princípio, quando o economista escreve que a formação desses empreendimentos é um pilar, quiçá possibilidade, de uma contrarrevolução socialista em curso. Já a vertente reformista, predominante nos dias atuais, observa na organização coletiva do trabalho uma nova forma de inserção no capitalismo, que adere ao capital, porém o faz de maneira e lógica reformadas, excluindo-se a segregação proprietário versus trabalhadores, colocando o trabalho e o indivíduo como foco.

A motivação da Prefeitura de Americana para formação da Cooperlírios estava dada em dois pontos principais, como apresentado: a) organizar a atividade dos catadores no local, tendo em vista que sua prática precária estava trazendo prejuízos à salubridade do bairro; b) garantir a manutenção econômica dessa atividade, dado que ela era relevante e, na maioria dos casos, a única fonte de renda dos indivíduos e das famílias praticantes da coleta.

Alinhada a esses objetivos, a justificativa da escolha dos moldes cooperativistas para a futura organização, conforme relatado pelo vereador líder do projeto, era a de que esse tipo de empreendimento não apenas garantiria de modo formal o principal objetivo de manutenção dessa atividade econômica (emprego), assim como seu marco institucional, baseado na igualdade e soli- 
dariedade, poderia levar a organização e seus indivíduos, de forma sustentada, à prosperidade.

Depreende-se, então, que a motivação norteadora da formação da Cooperlírios não ocorreu pelo princípio revolucionário de contestação do sistema. Não se buscou, quando da proposta da formação da cooperativa, a criação de um modelo de resistência ao capital, de características e bandeiras socialistas. Como frisou o vereador, o objetivo final era a ação pragmática de garantia formal de emprego, capaz de gerar renda e vida digna sustentadas para as famílias locais praticantes das atividades de coleta de recicláveis e/ou reutilizáveis.

Contudo, o histórico da formação da Cooperlírios indica que o aspecto pragmático não encerra sua principal motivação. A despeito de estar focada na questão de formalizar a atividade (emprego), a prefeitura vislumbrou no cooperativismo uma alternativa sustentada de prosperidade para os catadores. Não se focou o aspecto revolucionário de crítica ao sistema, mas se levou em consideração sua doutrina, seus princípios e seu arranjo organizacional. Ao optar pelo cooperativismo, a prefeitura pretendeu constituir empreendimento que não apenas garantisse o emprego com segurança institucional, mas, principalmente, que incitasse a formação de liame social, o qual pudesse gerar um contexto organizacional e social catalisadores da prosperidade do empreendimento e de seus indivíduos. De acordo com o vereador líder do projeto, "[...] durante esse processo todo, trabalhar para junto aos diferentes órgãos do poder público, de que era importante, era necessário investir na organização dessa empresa comunitária. E mais do que isso, por que empresa comunitária? Porque também ela tem o ganho social".

Com relação à forma e ao processo como a Cooperlírios foi constituída, observou-se em campo uma organização que nos termos do cooperativismo vive, em sua particularidade, os ideais do movimento. Trata-se, conforme seu Estatuto, de uma organização formada para defender seus cooperados por meio de ajuda mútua, dando-lhes, com isso, condições de exercer e fortalecer suas atividades profissionais, além de contribuir para seu meio social, por intermédio da preservação do meio ambiente (reciclagem). Mais claro ainda, com relação aos princípios do movimento cooperativista, tornam-se seus objetivos estatutários, os quais listam verbos de ação pelos quais se observa a essência dos preceitos do cooperativismo e da economia solidária. Em sua síntese, os objetivos estatutários da Cooperlírios determinam: 1) colocar a organização à disposição para auxiliar os cooperados em seu trabalho; 2) focar-se nos cooperados, sendo guiada por interesses coletivos; 3) promover e disseminar a educação cooperativista; e 4) buscar diálogo com o meio social - seja comunidade, governo ou universidade. 
No aspecto social, o perfil observado dos cooperados da Cooperlírios revela um brasileiro migrante intra e inter-regional de baixa renda e baixa escolaridade que, em situação de risco, migrou para cidades do eixo Ribeirão Preto-São Paulo (capital) em busca de oportunidades de trabalho, residindo na periferia das cidades e sobrevivendo, em sua grande maioria, da informalidade e de "bicos" no mercado de trabalho.

Pelas narrativas desses cooperados e a inserção no campo, constatou-se que a Cooperlírios melhorou consideravelmente a vida econômica da maioria. Tornou-se meio de renda, pelo qual o cooperado, mesmo possuindo renda variável por sua produtividade, declara que agora pode "abrir seu carnê de compra", pois sabe que ganhará dinheiro todo mês. Ao se tornarem cooperados, os indivíduos manifestaram sentir-se mais seguros com relação à renda, tratando-a como "salário". Inclusive, esse salário permitiu, conforme relatos, que houvesse alteração do mix de compra: passaram a consumir alguns tipos de carne de primeira, alimentos e, destacadamente, bens gerais de consumos: roupas, sapatos etc.

Do ponto de vista organizacional, a Cooperlírios mostrou-se bem ativa. A busca de seus cooperados, sempre em parceria com a prefeitura, é de constante e contínuo aperfeiçoamento dentro do modelo cooperativista e de seus princípios. A cada dia trabalhado e a cada curso frequentado, os cooperados parecem querer se aproximar mais do modelo, tomando ações nesse sentido.

\subsection{Dinâmica organizacional}

Dinâmica organizacional pode ser entendida, de maneira geral, como a forma processual cotidiana pela qual os trabalhos são executados em uma determinada organização. Trata-se, no limite, das relações e interações que são construídas e significadas entre os indivíduos, seus trabalhos e a estrutura organizacional, que dão sentido aos primeiros acerca de onde e como trabalham. Dessa forma, a dinâmica organizacional não apenas dita o modus operandi da organização, mas também influencia a vida dos indivíduos.

O estudo da dinâmica organizacional da Cooperlírios suscitou algumas experiências organizacionais particulares, densas de significados, que se tornaram portas de entrada interessantes para se constatar as influências que a vivência e o trabalho na Cooperlírios acabaram gerando nos cooperados. Nesse sentido, dois eventos destacaram-se por sua complexidade e desdobramentos teóricos: a dinâmica da autogestão e um incêndio na cooperativa. 


\subsubsection{Autogestão}

Idealmente, o modelo organizacional da cooperativa é caracterizado por uma organização focada no indivíduo, de princípios democráticos, cuja propriedade nas mãos dos cooperados considera cada indivíduo um sujeito ativo, livre, solidário e igualitário. O ser cooperado não é exclusivamente responsável pelo próprio trabalho, mas pelo todo organizacional. O cooperado, enquanto sujeito ativo, não responde apenas por suas atividades designadas, ou, ainda, estabelece interação apenas com um chefe/companheiros de departamento; ele assume um papel holístico, interagindo com todas as dimensões da organização.

Esse pressuposto normativo do princípio democrático da cooperativa é manifestado em sua dinâmica organizacional por meio de assembleias (autogestão). Nesse sentido, o arranjo organizacional da cooperativa pressupõe intensa interação social, na qual toda a gestão é discutida em arena aberta de debates. As assembleias acabam por ditar a dinâmica que não apenas aproxima os cooperados uns dos outros, mas, acima de tudo, abre espaço para diálogo, argumentação e participação. Tornam-se espaços incentivadores ao autoconhecimento e ao conhecimento da organização: ao refletir sobre seu trabalho e ter a oportunidade de opinar sobre sua gestão, o cooperado começa a exercitar sua capacidade argumentativa, participativa e reflexiva.

Essa dinâmica pôde ser observada na Cooperlírios por meio dos relatos que os cooperados fazem da experiência de serem seus próprios patrões, participando das assembleias e de reuniões informais sobre a gestão da cooperativa. $\mathrm{O}$ ato de trabalhar sem patrão, com responsabilidade não apenas de sua atividade individual, mas do todo organizacional, fez com que as assembleias e reuniões se tornassem influentes para muitos cooperados, tornando-se espaços de aprendizagem e ressignificação de personalidades e comportamentos individuais.

O primeiro processo observado está ligado ao relacionamento interpessoal dos cooperados e à exposição pública. Alguns cooperados que se achavam tímidos e/ou avessos à interação social e/ou à exposição pública, depois de experimentarem a gestão e a dinâmica organizacional cooperativa, admitiram que mudaram: estão socialmente mais "soltos" e menos tímidos. Desenvolveram maior dinâmica social, facilidade em fazer amizades e tratá-las, bem como competência crítica-argumentativa, pela qual conseguem expor suas opiniões em público, debatendo-as.

O segundo processo decorre do primeiro e, a partir da autogestão, está relacionado à experiência cívica e solidária. Como cada cooperado possui o direito e a liberdade de expor suas ideias diretamente ao outro, vivendo o exer- 
cício constante de análise dos limites de seus direitos e os dos outros, acaba por se desenvolver uma dinâmica em que os indivíduos começam a se posicionar constantemente, sentindo-se responsáveis pela condução dos processos, assim como parte determinante da gestão da organização. Há o sentimento coletivo de que a responsabilidade é de todos e cabe a cada um participar. Nessa dinâmica, as experiências vivenciadas em assembleias, caracterizadas por argumentação, reflexão e críticas diretas, desenvolveram nos cooperados da Cooperlírios certa aprendizagem social, marcada pela preocupação com o próximo, fundamentando-se, principalmente, na noção de direitos.

Essa dinâmica de crítica cotidiana na prática de trabalho cooperativista também gerou uma terceira influência. Como relataram os cooperados mais antigos da Cooperlírios, que mais participaram de assembleias, atualmente eles se sentem mais bem preparados para dialogar e debater sobre a organização em que trabalham. Não apenas manifestam grande conhecimento sobre o funcionamento da organização e de sua gestão, mas todos têm de prontidão uma sugestão para melhoria dos trabalhos. Os cooperados passam a desenvolver noções de administração, pelas quais começam a exercitar um pensamento gerencial.

Nesse sentido, conclui-se que esta gestão por princípio democrático, em dinâmica de assembleias, produziu no caso estudado um espaço dialógico e argumentativo, que influenciou em três pontos observados seus cooperados: a) o desenvolvimento de uma competência argumentativa que incentiva a interação social; b) a experiência da reflexão cívica e solidária, de preocupação com o próximo e com o todo (noções de direitos); e c) o desenvolvimento de competências gerenciais, por meio da aprendizagem, na práxis, de noções de administração.

\subsubsection{Incêndio}

Em pleno Dia das Mães de 2006, um incêndio de proporções devastadoras atingiu a Cooperlírios. Todo o material trabalhado e armazenado foi queimado. Naquele mês, toda a produção da Cooperlírios e a remuneração de seus cooperados foram perdidas. Esse triste evento, que marcou com cinzas a história da organização, foi suscitado durante os trabalhos de campo e nas entrevistas. Pelas narrativas do episódio, esse evento destacou-se como denso de significado, sendo porta de entrada interessante para se analisar um fator de extrema importância: a solidariedade entre os cooperados.

A solidariedade é um dos temas centrais do cooperativismo, da economia solidária e dos empreendimentos solidários. Esse termo não trata apenas 
da essência desses movimentos, mas o fim que se busca para a constituição de um liame social capaz de gerar a prosperidade sustentada de suas ações. Todavia, o fato de haver sua defesa não necessariamente garante sua manifestação na vida dos cooperados.

Por meio da análise das percepções dos cooperados e da prefeitura sobre o incêndio ocorrido na Cooperlírios foi possível constatar que a cooperativa conseguiu consolidar forte sentimento de solidariedade e apoio em seus cooperados, outrora inexistentes quando eram catadores de rua. O processo organizativo da Cooperlírios, desde sua formação até a vivência de seu cotidiano, gerou solidariedade dentro do grupo, que após o incêndio veio à tona com toda a força.

Conforme narrado, o clima tenso e triste na data do incêndio foi tomando aos poucos tom motivador e desafiador. Rapidamente, como uma Fênix, a Cooperlírios foi reconstruída de suas próprias cinzas. Mesmo sem estrutura e com suas bancadas queimadas, os cooperados começaram a trabalhar no chão, em meio às cinzas. Incrivelmente, apesar de uma situação mais precária, o clima entre eles melhorou, bem como a própria produção geral aumentou.

Analisa-se, por meio da reação dos cooperados ante o incêndio, que um dos principais objetivos da implementação de um empreendimento solidário, como a Cooperlírios, parece ter surtido resultados. Os catadores que anteriormente ao projeto atuavam de modo esparso pelo bairro, quando organizados em cooperativa, não apenas começaram a organizar essa atividade de modo mais eficiente e produtivo, mas também desenvolveram vínculo social, certa identidade que os une em torno do empreendimento e de seus trabalhos.

\section{Considerações finais}

Aventurar-se pela problemática de como os indivíduos formaram e vivenciam um empreendimento solidário suscitou algumas questões e eventos "bons para se pensar" (Lévi-Strauss, 1976) no campo dos estudos organizacionais.

Ao se analisar o processo organizativo (Spink, 1991, 1996) da Cooperlírios, foi possível observar como foi formado um grupo específico (prefeitura e catadores) que, com objetivos e interesses comuns, constituiu um empreendimento de características solidárias. Analisou-se a dinâmica do grupo desde sua origem até seu cotidiano hodierno, e, principalmente, como este grupo construiu o empreendimento e vivencia sua dinâmica organizacional.

A rica experiência no campo (com observação não participante, entrevistas e análise de documentos) permitiu destacar dois momentos relevantes 
no processo organizativo da Cooperlírios: sua formação e sua dinâmica organizacional. Por meio desses dois momentos foi possível examinar questões que contribuem para o debate dos estudos organizacionais, especificamente, na gestão humana e social das organizações, a saber: a) a ação viável para o desenvolvimento local; b) a construção de leitura particular dos preceitos doutrinários e organizacionais do cooperativismo; c) e, principalmente, a influência de seu arranjo e dinâmica organizacionais nos aspectos sociais e políticos da vida de seus trabalhadores.

Com relação à formação, a interpretação desse processo ensejou debate (revolucionário versus reformista), revelando que a Cooperlírios, quanto a sua motivação inicial, nasceu de um princípio pragmático, porém não abandonou as premissas e doutrinas do movimento cooperativista. Nesse caso, houve um alinhamento reformista-pragmático com as bases programáticas do cooperativismo e da economia solidária.

O objetivo da prefeitura, no primeiro momento, era o de organizar os trabalhos de coleta de materiais recicláveis e/ou reutilizáveis para melhoria do saneamento/salubridade do bairro e manutenção formal dessa atividade, garantindo emprego e renda. Percebe-se que a finalidade que orienta essa motivação é de natureza econômico-instrumental - a construção de um meio, uma organização formal, para consecução de um fim dado: saneamento e salubridade urbanos, emprego e renda. Entretanto, a escolha deliberada do meio para consecução dessa cadeia instrumental foi dada em torno da aposta em vínculo solidário, que um modelo específico, o cooperativismo, propugna como capaz de gerar. Nesse sentido, a opção do modelo cooperativista obteve sua finalidade na criação de vínculos específicos a partir de uma ótica substantiva, os quais pudessem constituir um liame social capaz de gerar prosperidade e sustentabilidade ao empreendimento.

Essa articulação entre uma lógica instrumental e substantiva é passível de ser bem articulada nos empreendimentos solidários e retoma os estudos de França Filho (2002). Os empreendimentos solidários, por sua natureza, possuem "capacidade de articular lógica de ação bastante diferenciadas na sua dinâmica" (França Filho, 2002:2). A compatibilidade entre eficiência econômica e lógica solidária está respaldada no conceito de economia plural, citado por França Filho (2002) a partir dos estudos de Polanyi. Nesse sentido, a análise da formação da Cooperlírios torna-se boa experiência para corroborar essa articulação e defendê-la.

Nesse processo da formação da cooperativa, indagou-se se as motivações de se constituir um empreendimento com eficiência econômica por meio de laços solidários realmente levariam, na dinâmica de seu processo organi- 
zativo, à realização desses objetivos. Subjacente a essa indagação, encontra-se a análise de como um grupo determinado, formado por interesses comuns, constrói, em sua prática particular, seus meios.

Os estudos do arranjo organizacional e da dinâmica de gestão da Cooperlírios levaram à interpretação de que a cooperativa, em sua particularidade, enquadra-se alinhada com os preceitos do movimento cooperativista e da economia solidária, adquirindo dimensões que lhe possibilitem ser entendida como empreendimento solidário (Gaiger, 1996, 2003).

Do primeiro ao sétimo princípio cooperativista (Pioneiros de Rochdale), a Cooperlírios vive à sua maneira todos os seus pressupostos. Os cooperados, agora identificados com o trabalho de seleção e reciclagem, mostram-se engajados em desenvolver o empreendimento, inclusive, utilizando-se para isso das diversas parcerias técnicas, principalmente, com a Prefeitura Municipal. Nesses termos, a Cooperlírios pode ser entendida como típica cooperativa defensiva (Lima, 2004) e autêntica (Singer, 1999, 2003). Defensiva, pois, como desenvolveu Lima (2004), trata-se de empreendimento formado por iniciativa governamental de geração de renda para populações pobres, a qual está alinhada com os princípios doutrinários do movimento cooperativista e da economia solidária. Essa interpretação da Cooperlírios como cooperativa defensiva e autêntica desdobra-se para a retomada de uma indagação proposta por França Filho (2002): seria a economia solidária um caminho para um novo modo de gestão pública?

O caso Cooperlírios abre espaço para essa problemática, demonstrando ser, apesar de alguns pontos abertos, uma experiência positiva e viável nesse sentido. Trata-se de um empreendimento constituído pelas relações entre governo municipal e a sociedade civil que apresentou resultados satisfatórios e eficazes: uma cooperativa em pleno funcionamento, que integra a cadeia do tratamento do lixo urbano da cidade, inserindo indivíduos na formalidade do trabalho, gerando não apenas renda, mas condições dignas de vida e influências sociais positivas.

Pela interpretação do modelo de gestão construído e sua dinâmica na Cooperlírios, observaram-se ainda alguns pontos fundamentais para a reflexão dos empreendimentos de economia solidária e as influências destes em seus indivíduos. Conforme o próprio discurso do movimento propugna, os incentivos à formação de empreendimentos solidários estão dados atualmente na busca por uma solução digna, por meio de emprego e renda, para as populações de baixa renda e baixa escolaridade em situação de risco. Nesse sentido, como desenvolve Singer (2000), tendo em vista o perfil dos indivíduos trabalhadores dos empreendimentos solidários, existe descrença genera- 
lizada na capacidade administrativa destes. Muitos consideram essa questão, inclusive, problema maior ao sucesso do empreendimento do que a própria reação do capitalismo e da dinâmica do mercado a esse tipo de iniciativa. Não obstante, como Singer (2000) argumenta, o conhecimento é um processo que acontece no devir do tempo, tanto como a maturidade da autogestão quanto a administração de todo o negócio.

$\mathrm{O}$ arranjo organizacional cooperativista estudado, somado à experiência de autogestão, influenciou a vida de seus cooperados por meio do desenvolvimento de algumas componentes educacionais e de aprendizagem, tanto técnica como social. A despeito de não possuírem formação técnica, a experiência de participar da autogestão desenvolveu na maioria dos cooperados consideráveis noções de administração, as quais se apresentaram como suficientes para uma boa condução gestora do empreendimento: os cooperados estruturam todo o modo de gestão, desenhando a divisão do trabalho que os remunera de maneira mais justa, produtiva e motivadora.

Mas não são somente noções de administração que os cooperados desenvolveram na vivência da gestão do empreendimento. Outros pontos, relacionados com dinâmica social, cívica e solidária, também se destacaram. Os cooperados manifestaram que, ao trabalhar na Cooperlírios, parecem estar mais aptos a argumentar e participar, bem como apresentam preocupação com o próximo e relativa capacidade de organização coletiva.

Estas observações suscitam debate interessante sobre o princípio democrático nas organizações, recuperando os estudos de Pateman (1992). Esta autora apresenta um seminal estudo sobre a participação no trabalho, abrindo o debate em torno dos reais princípios democráticos da autogestão versus as iniciativas gerencialistas de incentivo à participação dos anos 1960, como o toyotismo, a cogestão, entre outros. A questão que se coloca é: afinal, de qual participação estamos falando?

Em seu livro Participação e teoria democrática, Pateman (1992) revisita o papel da participação nas teorias da democracia e faz contundente crítica às imprecisões com que este conceito é utilizado nas análises de situações reais de trabalho pelos autores da administração. Nesses termos, Pateman analisa os tipos de exercício participativo dos trabalhadores nas organizações, definindo três tipos ideais: pseudoparticipação; participação parcial; e participação plena. De acordo com Pateman (1992:98), a participação plena faz referência aos trabalhadores autorregulados, tendo,

neste tipo de situação... [a não existência de] dois "lados" com poderes desiguais de decisão, mas um grupo de indivíduos iguais que têm de tomar suas 
próprias decisões a respeito da atribuição das tarefas e execução do trabalho [...] tal forma de participação consiste "num processo no qual cada membro isolado de um corpo deliberativo tem igual poder de determinar o resultado final das decisões".

Para Pateman (1992), o corolário que se tem do exercício desse tipo de participação seria a vivência democrática e igualitária ativa nas organizações, trazendo consigo um componente pedagógico, tendo como resultado o incentivo à participação cívica. Promoveria, ainda, uma cultura política, formadora de um indivíduo social e politicamente engajado.

A Cooperlírios consolida a existência de um princípio democrático, dado por argumentação em assembleia e votação, que pode, sim, ser palco de experiência muito próxima da participação plena (Pateman, 1992). Na Cooperlírios, mesmo sendo experimentada somente a dinâmica de votação, assumindo a possibilidade de influência nas decisões por determinados grupos (cooperados mais antigos; membros da Diretoria; e prefeitura), interpretou-se que, por meio dessa dinâmica assembleística, discussão e voto, há, nessa cooperativa, um processo democrático e pedagógico positivo para a sociabilidade, o civismo e a participação de seus cooperados. Os cooperados sentem-se mais sociáveis, preocupados com os demais (noções de direitos), identificados com seu trabalho, aptos à ação solidária, entre outros. Fatores que puderam ser constatados de modo geral no cotidiano dos trabalhos e nas narrativas dos cooperados, mas, destacada e simbolicamente, quando da organização coletiva para ressurgimento, das cinzas, de toda a organização.

Conclui-se que a dinâmica de organizações solidárias sustenta possíveis condições objetivas e subjetivas que podem favorecer transformações econômicas direcionadas para a humanização e a relativa emancipação, tomando os empreendimentos solidários dessa natureza não apenas como uma ação viável para o desenvolvimento local, mas, principalmente, como um arranjo organizacional que pode influenciar positivamente aspectos sociais e políticos da vida de seus trabalhadores, sendo, nesses termos, incentivados como mecanismos de políticas públicas para redução da desigualdade e resgate da cidadania.

\section{Referências}

BRASIL. Ministério do Trabalho e Emprego (MTE). Brasília, DF. Disponível em: <www.mte.gov.br>. Acesso em: 10 jul. 2006. 
BUBER, M. O socialismo utópico. São Paulo: Perspectiva, 2005.

CASTELLS, M. A sociedade em rede. São Paulo: Paz e Terra, 1999.

COFFEY, A.; ATKINSON, P. Making sense of qualitative data. Thousand Oaks: Sage, 1996.

CULTI, M.N. O cooperativismo popular no Brasil: importância e representatividade. In: TERCER CONGRESO EUROPEO DE LATINOAMERICANISTAS, 2002, Amsterdã. Disponível em: <www.humanas.unisinos.br/pesquisa/ecosol/txt/coopop.pdf >. Acesso em: 10 dez. 2006.

CUNHA, G.C. Dimensões da luta política nas práticas de economia solidária. In: SOUZA, A.R.; CUNHA, G.C.; DAKUZAKU, R.Y. (Org.). Uma outra economia é possível. São Paulo: Contexto, 2003.

DENZIN, N.K.; LINCOLN, Y.S. Introduction: entering the field of qualitative research. In: (Ed.). Handbook of qualitative research. Thousand Oaks: Sage, 1994.

ENGELS, F. A situação da classe trabalhadora na Inglaterra. São Paulo: Boitempo, 2002.

FRANÇA FILHO, G.C. A problemática da economia solidária: um novo modelo de gestão pública? In: ENCONTRO NACIONAL DA ASSOCIAÇÃO NACIONAL DE PÓS-GRADUAÇÃO EM ADMINISTRAÇÃO, 26, 2002, Salvador. Anais... Salvador, 2002.

GAIGER, L.I. Empreendimentos solidários: uma alternativa para economia popular. In: (Org.). Formas de combate e de resistência à pobreza. São Leopoldo: Unisinos, 1996.

. Empreendimentos econômicos solidários. In: CATTANI, A.D. (Org.). A outra economia. Porto Alegre: Veraz Editores, 2003.

GODOI, C.K.; BALSINI, C.P.V. A pesquisa qualitativa nos estudos organizacionais brasileiros: uma análise bibliométrica. In: ; BANDEIRA-DE-MELLO, R.; SILVA, A.B. (Org.). Pesquisa qualitativa em estudos organizacionais: paradigmas, estratégias e métodos. São Paulo: Saraiva, 2006.

GODOY, A.S. Estudo de caso qualitativo. In: GODOI, C.K.; BANDEIRA-DE-MELLO, R; SILVA, A.B. (Org.). Pesquisa qualitativa em estudos organizacionais: paradigmas, estratégias e métodos. São Paulo: Saraiva, 2006.

HARTLEY, J.F. Case studies in organizational research. In: CASSEL, C.; SYMON, G. (Ed.). Qualitative methods in organizational research. London: Sage. 1999. 
IAMAMOTO, M. A questão social no capitalismo. Temporalis, v. 2, n. 3, p. 9-31, 2001.

LECHAT, N.M.P. As raízes históricas da economia solidária e seu aparecimento no Brasil. In: SEMINÁRIO DE INCUBADORAS TECNOLÓGICAS DE COOPERATIVAS POPULARES, 2., 2002, Campinas. Anais eletrônicos... Disponível em: <www.itcp. unicamp.br/downloads/ext_doc2.doc>. Acesso em: 21 jul. 2006.

LÉVI-STRAUSS, C. O pensamento selvagem. São Paulo: Nacional, 1976.

LIBONI, M.T.L. A empresa de autogestão: uma visão psicossocial. Maringá, 2002. 126 f. Dissertação (mestrado em administração) — Ciências Sociais Aplicadas, Departamento de Administração, Universidade Estadual de Maringá, Maringá, 2002.

LIMA, J.C. O trabalho autogestionário em cooperativas de produção: o paradigma revisitado. Revista Brasileira de Ciências Sociais, v. 19, n. 56, p. 45-62, 2004.

MARX, K. O capital. São Paulo: Nova Cultura, 1995.

MERRIAM, S.B. Qualitative research and case study applications in education. San Francisco: Jossey-Bass, 1998.

NASCIMENTO, C. Autogestão e o novo cooperativismo. Brasília: Ministério do Trabalho e Emprego, 2004. (Texto para discussão). Disponível em: <www.mte.gov. br/ecosolidaria/prog_autogestaocooperativismo.pdf>. Acesso em: 10 jul. 2006.

OLIVEIRA, A.R.N. Identidade e transformação na economia solidária: a trajetória de vida de Luciene. 2005. 136 f. Dissertação (mestrado em administração) — Escola de Administração, Universidade Federal da Bahia, Salvador, 2005.

PATEMAN, C. Participação e teoria democrática. São Paulo: Paz e Terra, 1992.

SATO, L. Djunta-mon: o processo de construção de organizações cooperativas. Psicologia USP, v. 10, n. 2, p. 219-225, 1999.

SILVA JÚNIOR, J.T. Gestão, fato associativo \& economia solidária: a experiência da Asmocomp/Banco Palmas. 2004. 99 f. Dissertação (mestrado em administração) — Escola de Administração, Universidade Federal da Bahia, Salvador, 2004.

SINGER, P. Globalização e desemprego: diagnóstico e alternativas. Petrópolis: Vozes, 1998a. 1998b.

. Uma utopia militante: repensando o socialismo. São Paulo: Contexto, . Cooperativismo e sindicatos no Brasil. 1999. Disponível em: <www.cut.org. br>. Acesso em: 23 jan. 2006. 
. Economia solidária: um modo de produção e distribuição. In: SINGER, P.; SOUZA, A.R. (Org.). A economia solidária no Brasil: a autogestão como resposta ao desemprego. São Paulo: Contexto, 2000.

. Introdução à economia solidária. São Paulo: Contexto, 2002.

. Economia solidária. In: CATTANI, A.D. (Org.). A outra economia. Porto Alegre: Veraz Editores, 2003.

SOUZA, A.R. Economia solidária: um movimento nascente da crise do trabalho. In: ___ C CUNHA, G.C.; DAKUZAKU, R.Y. (Org.). Uma outra economia é possível. São Paulo: Contexto, 2003.

STAKE, R.E. Case studies. In: DENZIN, N.K.; LINCOLN, Y.S. (Ed.) Handbook of qualitative research. $2^{\text {nd }}$ ed. Thousand Oaks: Sage, 2000.

SPINK, P. O resgate da parte. Revista de Administração da USP, v. 26, n. 2, p. 2231, 1991.

. A organização como fenômeno psicossocial: notas para uma redefinição da psicologia do trabalho. Psicologia e Sociedade, v. 8, n. 1, p. 174-192, 1996.

WAUTIER, A.M.T.G.E. A economia social na França. In: CATTANI, A.D. (Org.). A outra economia. Porto Alegre: Veraz Editores, 2003.

. As relações de trabalho nas organizações de economia solidária: um paralelo Brasil-França. 2004. 253 f. Tese (doutorado em sociologia) — Instituto de Filosofia e Ciências Humanas, Universidade Federal do Rio Grande do Sul, Porto Alegre, 2004. 